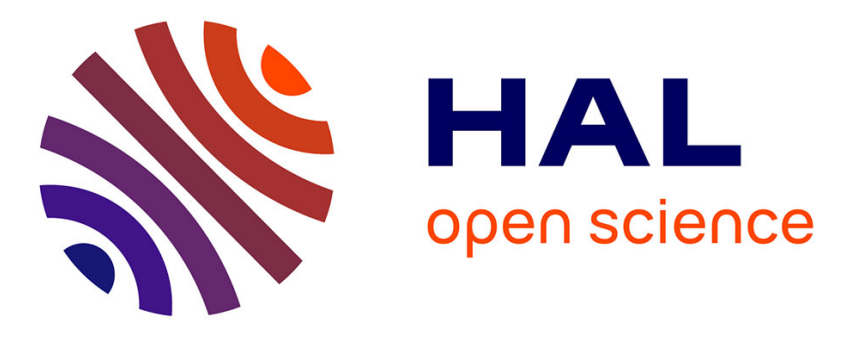

\title{
New solid fully-aperiodic large pitch fibers with non-filamented core for high-power singlemode emission
}

Romain Dauliat, Aurélien Benoit, Dia Darwich, Jens Kobelke, Kay Schuster, Stephan Grimm, Raphaël Jamier, François Salin, Philippe Roy

\section{- To cite this version:}

Romain Dauliat, Aurélien Benoit, Dia Darwich, Jens Kobelke, Kay Schuster, et al.. New solid fully-aperiodic large pitch fibers with non-filamented core for high-power singlemode emission. Advanced Solid State Lasers Conference, OSA, Oct 2015, Berlin, Germany. pp.AW2A.2., 10.1364/ASSL.2015.AW2A.2 . hal-01239316

\section{HAL Id: hal-01239316 https://hal.science/hal-01239316}

Submitted on 4 Jan 2016

HAL is a multi-disciplinary open access archive for the deposit and dissemination of scientific research documents, whether they are published or not. The documents may come from teaching and research institutions in France or abroad, or from public or private research centers.
L'archive ouverte pluridisciplinaire HAL, est destinée au dépôt et à la diffusion de documents scientifiques de niveau recherche, publiés ou non, émanant des établissements d'enseignement et de recherche français ou étrangers, des laboratoires publics ou privés. 


\title{
New solid fully-aperiodic large pitch fibers with non- filamented core for high-power singlemode emission
}

\author{
Romain Dauliat, ${ }^{1,2}$ Aurélien Benoît, ${ }^{1}$ Dia Darwich, ${ }^{1}$ Jens Kobelke, ${ }^{2}$ Kay Schuster, ${ }^{2}$ Stephan Grimm, \\ Raphaël Jamier, ${ }^{1}$ François Salin ${ }^{3}$ and Philippe Roy ${ }^{1}$ \\ ${ }^{1}$ Univ.Limoges, CNRS, XLIM, UMR 7252, F-87000 Limoges, France \\ ${ }^{2}$ Leibniz Institute of Photonic Technology, Albert-Einstein-Straße 9, 07745 Jena, Germany \\ ${ }^{3}$ Eolite Systems, 11 avenue de la Canteranne 33600 Pessac, France \\ Author e-mail address: romain.dauliat@xlim.fr
}

\begin{abstract}
We report on the first high power laser emission of a solid triple-clad fully-aperiodic large mode area fiber with non-filamented core based on Repusil process. The average power is $184 \mathrm{~W}$ with a singlemode fashion.

OCIS codes: (140.3510) Lasers, fiber; (060.2280) Fiber design and fabrication; (060.5295) Photonic crystal fibers; (140.3295) Laser beam characterization; (160.2290) Fiber materials
\end{abstract}

\section{Introduction}

Microstructured-based fiber lasers have stimulated a perpetual research interest over the last two decades, dealing progressively with major key hindrances such as non-linear processes (in particular the Stimulated Brillouin Scattering), long-term degradations (pointing stability and photo-darkening) or more recently modal instabilities that hamper the power scaling [1]. Recent progresses achieved on fiber design, material synthesis and fiber fabrication have been beneficial both for continuous wave and pulsed high-power operations [2]. Among them, one may notice the intensive development of short length microstructured fiber architectures (Large-Pitch-Fibers (LPF) [3], Distributed Modal Filtering fibers (DMF) [4], Aperiodic LPF [5] ...) aiming for a robust singlemode emission in highpower regime. The major restriction for having access to such a Very-Large-Mode-Area (VLMA) fiber concerns the refractive index of the gain material that must strictly match that of the surrounding glass material (typically made of pure silica). Nevertheless, satisfying this objective with the conventional CVD techniques is not straightforward due to an insufficient control on the refractive index value. To circumvent this issue, fiber manufacturers produce filamented-core materials by resorting to a multiple stack-and-draw approach which is time-consuming and cost ineffective. As an alternative, a recently developed synthesis technique based on the powder technology and known as Repusil, has shown excellent performances for the fabrication of high-power fiber lasers [6] and for the enhancement of the control over the refractive index value, homogeneity and reproducibility [7]. In this context, authors report on the first high-power laser operation achieved into an Yb-doped solid Fully-Aperiodic Large-PitchFiber (FA-LPF) based on a non-filamented Repusil-made active core.

\section{Fiber concept}

This work relies on an original concept of triple clad VLMA fibers refer to as Fully-Aperiodic LPF (FA-LPF) as the cladding microstructuration is designed in an aperiodic fashion, as shown in figure 1(b). Such an aperiodic cladding allows for exacerbating the delocalization of high-order modes out of the gain region and thereby, reinforcing the singlemodeness and the thermal resilience. As reported in [8], this fiber structure could offer an improvement by half in emitted power before onset of a multimode trend. Unlike most of the common VLMA fibers, the restriction on the core refractive index to match that of the surrounding ground material is released, enabling for tailored doping of the 19-cells composing the high-index Yb-doped core (in red in figure 1). Thus, the fiber laser can afford an efficient mitigation of photodarkening $[9,10]$ and Brillouin gain [11] because of a real freedom in core glass composition. Hence, a robust singlemode operation is ensured by introducing an aperiodic pattern of low-index inclusions (made of pure silica for instance) into a high-index passively doped ground material (in light blue in figure 1). However, as for standard VLMA fibers, a perfect index-matching between the gain material and the surrounding passive glass (high-index one in the present case) has to be satisfied. Then, these materials are embedded into a pure silica trench (in dark blue in figure 1), making the fiber modal content independent from the air-clad dimensions, and so insensitive to avoided-crossings that can impact the fundamental mode in air-silica LPF design if the air-clad size is not properly chosen [12]. Finally, an air-clad (in yellow in figure 1) is implemented to ensure the propagation of the multimode pump radiation, leading to the so-called triple-clad design. One may know that the fiber concept has already been validated as passive fiber [13].

Additionally to the concept guidelines, another challenge has been intended to be taken up here. This work aspired in producing the gain material from a single drawing, resulting in a non-filamented core. This means that the fiber 
core will be fully-doped, whereas with the multiple stack-and-draw technique, the active material is diluted with a passive low-index material to ensure the index-matching targeted. Moreover, a lower concentration in rare-earth ions is required to reach an equivalent gain, resulting in a reduced sensitivity to the photodarkening.

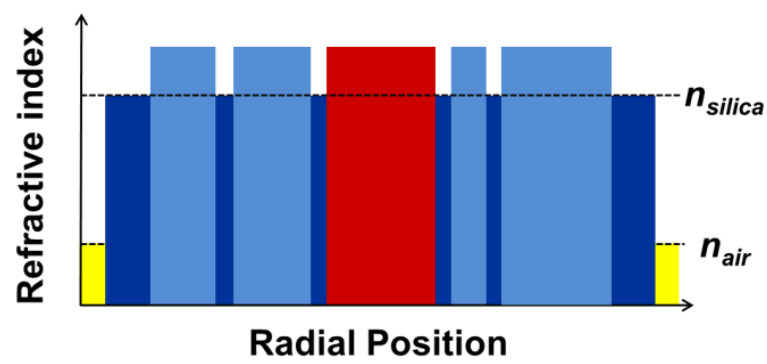

(a)

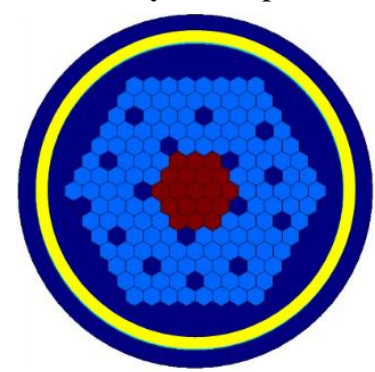

(b)

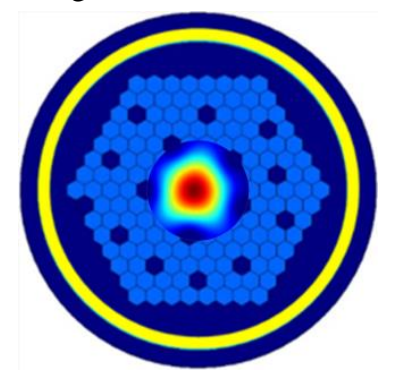

(c)

Fig. 1: (a) Schematic representation of the refractive index profile and (b) Cross-section of the triple-clad fully aperiodic fiber. The gain region is represented in red, the index-matched passive material in light blue, the pure silica inclusions and trench are depicted in dark blue whereas the yellow area stands for the air-clad. (c) Computed intensity distribution of the fundamental mode propagated into the FA-LPF.

To fulfil this objective, doped materials have been synthetized by a non-CVD technique, the REPUSIL-technique based on the sintering and vitrification of doped powders. This method offers some major advantages such as the potential of producing large volume of high purity doped silica glass (2 times more than the MCVD) while preserving a high degree of control over the refractive index value, homogeneity and reproducibility of about 1 to $2.10^{-4}$. Ultimately, a unique step of stack and draw is performed so as to assemble the whole structure.

\section{Experimental results}

The cross-section of the fabricated Yb-doped solid FA-LPF is depicted in figure 2(a), where the bright region stands for both high-index materials (actively and passively doped) while the grey areas are made of pure silica. This rod-type fiber (external diameter of $1.2 \mathrm{~mm}$ ) presents an average core diameter of about $40 \mu \mathrm{m}$, yielding into a mode field area of $920 \mu \mathrm{m}^{2}$. The high-index inner cladding has a hexagonal shape with a flat-to-flat diameter of $105 \mu \mathrm{m}$ and a vertex-to-vertex diameter of $128 \mu \mathrm{m}$. The air-clad (dark area in figure 2(a)) exhibits an internal diameter of $210 \mu \mathrm{m}$ $(\mathrm{NA}=0.4)$. The laser behavior has been characterized by placing a $60 \mathrm{~cm}$-piece of this triple-clad rod-type fiber into the laser cavity schematically depicted in figure 2(b). The latter is formed by a high-reflectivity broadband dichroic mirror above $1.03 \mu \mathrm{m}$ (noted $\mathrm{M} 2$ in the schema) and the output end-facet of the fiber under test cleaved at $0^{\circ}$ (Fresnel reflection at $4 \%)$, the $\mathrm{Yb}$-doped FA-LPF being pumped using a $400 \mathrm{~W}$ fibered $\left(\mathrm{D}_{\text {core }}=400 \mu \mathrm{m}, \mathrm{NA}=0.22\right)$ multimode diode $(\lambda=980 \mathrm{~nm})$.

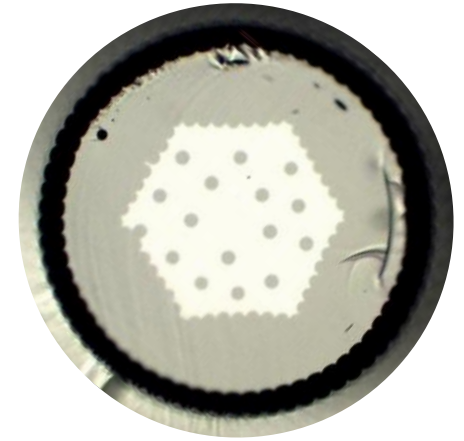

(a)

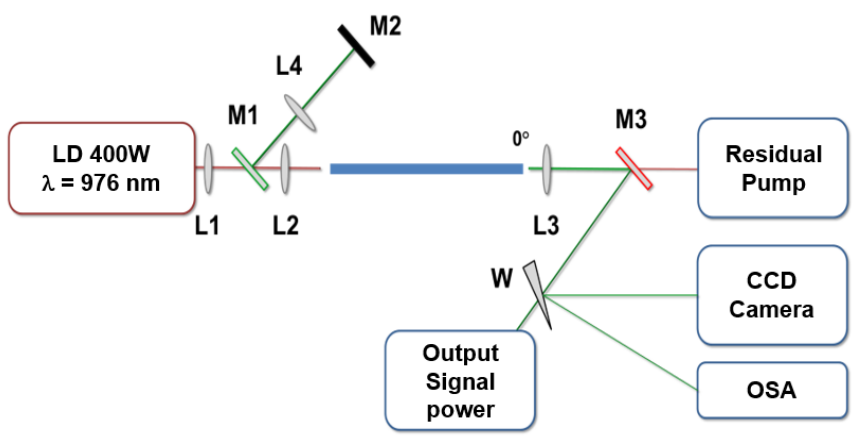

(b)

Fig. 2: (a) Image of the cross-section of the fabricated Yb-doped FA-LPF. (b) Schematic representation of the experimental fiber laser set-up composed of the active rod-type fiber (blue thick line), a set of dichroic mirrors (M1: $0^{\circ} \mathrm{AR} @ 980 \mathrm{~nm}, 22.5^{\circ} \mathrm{HR} @ 1030, \mathrm{M} 2: 0^{\circ} \mathrm{HR} @ 1030$,

M3: $0^{\circ}$ AR@980nm, 22.5 HR@1030), four lenses (L) and a levy window (W). The green (red) lines represent the signal (pump) beam propagation.

The evolution of the extracted laser power with respect to the incident pump power is shown in figure 3(a). First of all, due to a non-optimized air-clad size inducing a non-optimized core to air-clad ratio, the linear absorption was kept moderate, resulting in a non-negligible amount of residual pump power. The slope efficiency with respect to the pump power has reached $46 \%$. Further efforts will be carried on the optimization of the air-clad dimensions. Figure 3(b) depicts the near-field intensity distributions collected for four different signal output powers: $15.9 \mathrm{~W}, 76.2 \mathrm{~W}, 130 \mathrm{~W}$ and $184 \mathrm{~W}$ (corresponding to the maximal extracted power). The intensity pattern is quite faithful with that obtained 
numerically (see figure 1(c)) although the beam quality has to be verified. As addressed before, the beam quality is highly dependent to the index-matching between the active and passive high-index materials. For this reason, a refractive index measurement was performed with a commercial multifocus tomograph (IFA-100 from Interfiber Analysis) on a reference step-index fiber composed of these two glasses (the active material being the core and the passive material the cladding). It is worth noting that no index-mismatch was observed during the measurement, letting us think that the index-matching could be valid in the range of the system accuracy, which is of $+/-1.10^{-4}$.

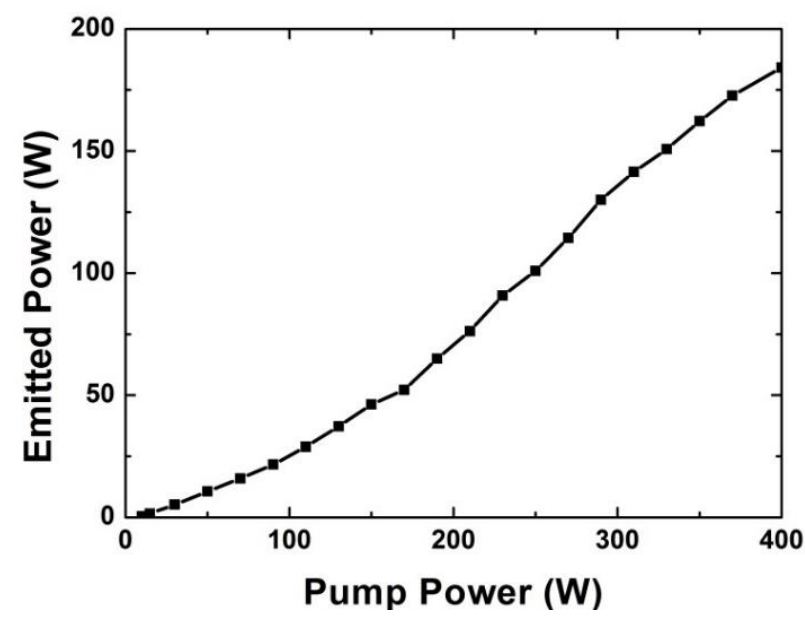

(a)

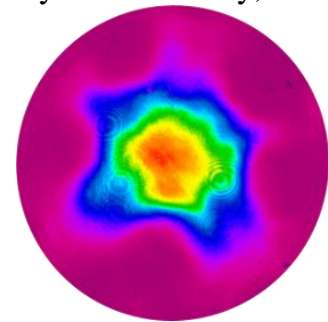

(b)

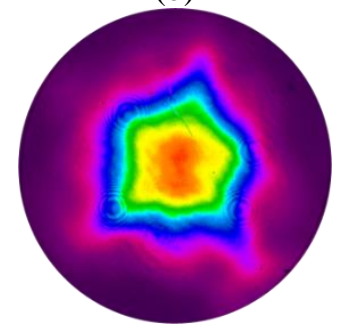

(d)

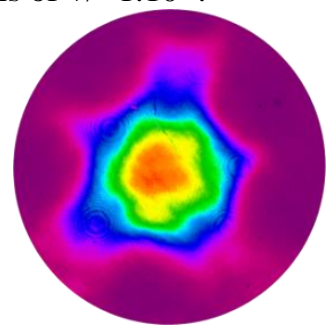

(c)

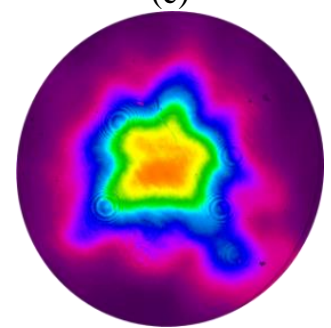

(e)

Fig. 3: (a) Evolution of the extracted output power versus the incident pump power. Image of the near-field intensity distributions measured for different output power: (b) $15.9 \mathrm{~W}$, (c) $76.2 \mathrm{~W}$, (d) $130 \mathrm{~W}$ and (e) $184 \mathrm{~W}$.

An experimental observation has allowed to estimate an index-mismatch of $5.10^{-5}$ to $1.10^{-4}$, which represents the best index-matching achieved from a homogeneous $\mathrm{Al} / \mathrm{Yb}$-doped core material. Under these conditions, a numerical simulation suggests that the fiber is few-modes (less than four). Several experimental analyses of the beam quality are currently ongoing and will be commented at the conference. Additionally using a longer fiber sample of $90 \mathrm{~cm}$, the emitted power was increased up to $202 \mathrm{~W}$ at the maximum pump power.

\section{Conclusion}

The fabrication of the first solid triple-clad Fully-Aperiodic Large-Pitch-Fiber made of a non-filamented Yb-doped core is reported. Although the index-matching is not yet perfect, this work demonstrates the highest degree of refractive index control noticed to date. Moreover, an efficient laser operation has been observed up to $184 \mathrm{~W}$ as well as a promising beam quality. Further improvements as the optimization of the core to air-clad ratio or an optimal index-matching are currently undergoing.

This work, conducted under the AVANTAGE project, was co-funded by the European Union and Eolite Systems. $E C$ is involved in the Région Limousin with the "Fonds européen de développement économique et régional". Financial support by the Thuringian Ministry of Economics, Labor, and Technology (TMWAT) under contract 2011 FGR 0104 (FG Faser-Tech), with financial support from the European Social Fund (ESF) is gratefully acknowledged.

\section{References}

[1] E. Eidam et al., Opt. Exp. Vol. 19, no. 14, pp. 132018-13224, (2011)

[2] M.N. Zervas et al., IEEE Journal of selected topics in Quantum Electronics, 20, 5, (2014)

[3] J. Limpert, et al., Light Sci. Appl., vol. 1, e8 (2012)

[4] E. Coscelli et al. J. Light. Technol., vol. 30, no. 22, pp. 3494-3499, (2012)

[5] R. Dauliat et al., in Proc. SPIE 9128, Micro-structured and Specialty Optical Fibres III, 2014, p. 912807.

[6] M. Leich, et al. Opt. Lett., vol. 36, no. 9, pp. 1557 - (2011)

[7] A. Langner et al. Proc. SPIE 6873, (2008)

[8] R. Dauliat et al. in Proc. SPIE 9507, Micro-structured and Specialty Optical Fibres, p. 950709, (2015)

[9] S. Jetschke et al. Appl. Opt., vol. 51, no. 32, pp. 7758-7764, (2012)

[10] M. Engholm et al., Opt. Lett., vol. 34, no. 8, pp. 1285-1287, (2009)

[11] P. D. Dragic et al., Opt. Mat., vol. 35, pp. 1627-1632, (2013)

[12]F. Jansen et al., Opt. Exp., vol. 19, no. 14, pp. 13578-89, (2011)

[13] A. Benoît et al., Opt. Lett, vol. 39, no.15, pp 4561-4564, (2014). 